Article

\title{
Alpha-Glucosidase Inhibitory Effect of Psychotria malayana Jack Leaf: A Rapid Analysis Using Infrared Fingerprinting
}

\author{
Tanzina Sharmin Nipun ${ }^{1,2}$, Alfi Khatib ${ }^{1,3, *}$, Qamar Uddin Ahmed ${ }^{1} \mathbb{D}$, Irna Elina Redzwan ${ }^{1}$, \\ Zalikha Ibrahim $\left.{ }^{1}{ }^{(}\right)$, Al'aina Yuhainis Firus Khan ${ }^{4}{ }^{1}$, Riesta Primaharinastiti ${ }^{3, *}$, \\ Shaden A. M. Khalifa ${ }^{5, *}$ and Hesham R. El-Seedi ${ }^{5,6,7}$ \\ 1 Pharmacognosy Research Group, Department of Pharmaceutical Chemistry, Kulliyyah of Pharmacy, \\ International Islamic University Malaysia, Kuantan 25200, Pahang Darul Makmur, Malaysia; \\ tsn.np99@gmail.com (T.S.N.); quahmed@iium.edu.my (Q.U.A.); elina@iium.edu.my (I.E.R.); \\ zalikha@iium.edu.my (Z.I.) \\ 2 Department of Pharmacy, Faculty of Biological Sciences, University of Chittagong, \\ Chittagong 4331, Bangladesh \\ 3 Faculty of Pharmacy, Airlangga University, Surabaya 60155, Indonesia \\ 4 Department of Biomedical Sciences, Kulliyyah of Allied Health Sciences, International Islamic University \\ Malaysia, Kuantan 25200, Pahang Darul Makmur, Malaysia; alainayuhainis@gmail.com \\ 5 Department of Molecular Biosciences, The Wenner-Gren Institute, Stockholm University, \\ SE-106 91 Stockholm, Sweden; hesham.elseedi@su.se \\ 6 Department of Chemistry, Faculty of Science, Menoufia University, Shebin El-Kom 32512, Egypt \\ 7 International Research Center for Food Nutrition and Safety, Jiangsu University, Zhenjiang 212013, China \\ * Correspondence: alfikhatib@iium.edu.my (A.K.); r.nastiti@gmail.com (R.P.); shaden.khalifa@su.se (S.A.M.K.)
}

Academic Editor: Julian Weghuber

Received: 14 August 2020; Accepted: 8 September 2020; Published: 11 September 2020

Abstract: The plant Psychotria malayana Jack belongs to the Rubiaceae family and is known in Malaysia as "meroyan sakat/salung". A rapid analytical technique to facilitate the evaluation of the P. malayana leaves' quality has not been well-established yet. This work aimed therefore to develop a validated analytical technique in order to predict the alpha-glucosidase inhibitory action (AGI) of P. malayana leaves, applying a Fourier Transform Infrared Spectroscopy (FTIR) fingerprint and utilizing an orthogonal partial least square (OPLS). The dried leaf extracts were prepared by sonication of different ratios of methanol-water solvent $(0,25,50,75$, and $100 \% v / v)$ prior to the assessment of alpha-glucosidase inhibition (AGI) and the following infrared spectroscopy. The correlation between the biological activity and the spectral data was evaluated using multivariate data analysis (MVDA). The $100 \%$ methanol extract possessed the highest inhibitory activity against the alpha-glucosidase ( $\mathrm{IC}_{50} 2.83 \pm 0.32 \mu \mathrm{g} / \mathrm{mL}$ ). Different bioactive functional groups, including hydroxyl $(\mathrm{O}-\mathrm{H})$, alkenyl $(\mathrm{C}=\mathrm{C})$, methylene $(\mathrm{C}-\mathrm{H})$, carbonyl $(\mathrm{C}=\mathrm{O})$, and secondary amine $(\mathrm{N}-\mathrm{H})$ groups, were detected by the multivariate analysis. These functional groups actively induced the alpha-glucosidase inhibition effect. This finding demonstrated the spectrum profile of the FTIR for the natural herb P. malayana Jack, further confirming its medicinal value. The developed validated model can be used to predict the AGI of $P$. malayana, which will be useful as a tool in the plant's quality control.

Keywords: Psychotria malayana; $\alpha$-glucosidase inhibition; orthogonal partial least square; fingerprint; infrared spectroscopy analysis

\section{Introduction}

The long-term metabolic disease produced by hyperglycemia is known as diabetes mellitus (DM), referring to a condition where a consistently high blood sugar level leads to an imbalance of tissue 
homeostasis. Various complications may develop if diabetes is not well managed; for instance, it can cause cardiovascular diseases and stroke [1]. Myopia, glaucoma, and retinal detachment may be caused by diabetic retinopathy [1]. The World Health Organization (WHO) has categorized three main variants of diabetes mellitus and identified it as a heterogeneous metabolic disease with high blood sugar [2]: type-1, insulin-dependent diabetes (T1DM); type-2, non-insulin-dependent diabetes (T2DM); and a third, gestational diabetes mellitus (GDM).

T2DM predominantly affects obese adolescent children and has been observed more in older individuals [2]. T2DM represents most of the cases worldwide [1]. The WHO had identified several T2DM risk factors, including genetics, race, and age [1]. Others include obesity, poor diet, lack of physical activity, and tobacco. It is the most familiar form of diabetes and has reached epidemic proportions in most parts of the world [3]. This could be aligned with current lifestyles [4]. The number of diabetic patients substantially increased between 1980 and 2014, and in 2014, 422 million people over the age of 18 were recorded as having diabetes [1]. In 2012, 1.5 million deaths were caused by diabetes, with the majority of cases T2DM [1]. Every year, 1.4 million Americans are diagnosed with diabetes, and if this trend continues, one in three Americans will suffer from diabetes by 2050 [5].

Medicinal plants have traditionally been consumed in different cultures to cure diabetes. The genus Psychotria has many applications in conventional medicine and provides tremendous potential for pharmacological properties. The genus Psychotria is traditionally known among the Karo people of North Sumatra as a treatment for diabetes, named "loning"; it is also called "meroyan sakat/salung" in Malaysia [6]. Psychotria malayana Jack is a plant of the Rubiaceae family and has several synonyms: Grumilea aurantiaca, Pilosella aurantiaca, Chassalia expansa, Psychotria stipulacea, and Uragoga malayana. Hadi et al. [7] reported the derivation of major alkaloids, hodgkinsine, and other compounds, including calycanthine, (+/-)-chimonanthine, meso-chimonanthine, 3-methyl-1,2,3,4-tetrahydro- $\gamma$-carboline, and 2-methyl-6-methyl pyrazine, from P. malayana leaves. Further, Hadi [8] studied the anti-bacterial activities of LPM-574, which is a derivative of hodgkinsine. Matsuura et al. [9] investigated the analgesic activities of hodgkinsine, (+)-chimonanthine, and meso-chimonanthine, whereas Chebib et al. [10] demonstrated the anti-convulsant effect of calycanthine. Despite scientific reports of the plant's activities, data on its anti-diabetic impact are scarce.

Fourier Transform Infrared Spectroscopy (FTIR) is one of the most widely used techniques for the identification of chemical constituents and the elucidation of structural compounds. It has been used as a main method for identifying medicines in many countries [11]. FTIR analysis offers rapid fingerprint screening of the plant extracts [12]. Asokkumar et al. [12] indicated the application of FTIR in profiling natural herbs, including Solanum torvum, Phyllanthus amarus, Phyllanthus maderaspatensis, and Senna auriculata. In addition, Nagarajan et al. [11] carried out an FTIR study to detect the active functional groups present in garlic powder (Allium sativum).

No report of the correlation of the alpha-glucosidase inhibition (AGI) activity of the P. malayana leaf extract to its infrared spectrum has been made yet. In this study, therefore, an attempt is made to examine the bioactive compound functional groups that are present in the leaf extracts (in various solvents ratios of methanol-water) by using the FTIR technique. The present study attempted to develop a multivariate calibration model to predict the AGI activity of $P$. malayana Jack leaf extracts in correlation to their FTIR spectra.

The AGI enzyme suppresses glucose absorption by $\alpha$-glucosidase enzyme (AGE) inhibition, which is an effective therapeutic strategy for the treatment of T2DM. The percentage of hydrolytic cleavage of oligosaccharides can be decreased by stopping the action of alpha-glucosidase, slowing the general rate of glucose absorption into the blood [13]. The goal of this work is to develop a calibration model able to evaluate metabolite fingerprint quality in relation to the FTIR spectrum. 


\section{Results and Discussion}

\subsection{Extraction Yield}

The extraction yield of P. malayana leaf extracts is displayed in Table 1. The yield \% of the solvent dilutions differed considerably from each other $(p<0.05)$. The 75\% solvent ratio of methanol-water extracts of $P$. malayana resulted in the highest yield $(35.19 \pm 1.11 \%)$. In comparison, the $0 \%$ methanol-water extract was found to have the lowest percentage of yield $(20.40 \pm 1.47)$. The trend of this result was found as 75\% $>50 \%>100 \%>25 \%>0 \%$. From this result, it is observed that to get a higher yield of extraction, a solvent of medium polarity is preferable to that of higher polarity. This result further indicated that a high proportion of methanol could be the perfect solvent for increasing extraction yields. This is in agreement with Khatib et al. [14], where a higher yield of extraction was related to the water-alcohol combinations rather than the monocomponent solvent. Sultana et al. [15] also reported that aqueous methanol is the most suitable solvent for extracting the leaves of a medicinal plant with a higher yield of extraction.

Table 1. Alpha-glucosidase inhibition (AGI) activity $\left(\mathrm{IC}_{50}\right)$ and the percentage of yield of Psychotria malayana leaf extracts.

\begin{tabular}{|c|c|c|}
\hline Ratios of Methanol and Water. & AGI Activity IC I0 $(\mu \mathrm{g} / \mathrm{mL})$ & Percentage of Yield \\
\hline $0 / 100$ & $7.48 \pm 0.51^{b}$ & $20.40 \pm 1.47^{\mathrm{d}}$ \\
\hline $25 / 75$ & $5.45 \pm 0.51^{\mathrm{c}}$ & $28.67 \pm 1.01^{c}$ \\
\hline $50 / 50$ & $7.35 \pm 0.66^{b}$ & $32.73 \pm 1.41^{\mathrm{a}, \mathrm{b}}$ \\
\hline $75 / 25$ & $10.34 \pm 0.52^{a}$ & $35.19 \pm 1.11^{\mathrm{a}}$ \\
\hline $100 / 0$ & $2.83 \pm 0.32^{d}$ & $31.51 \pm 1.24^{b}$ \\
\hline Quercetin & $1.86 \pm 0.04^{\mathrm{d}}$ & ND \\
\hline
\end{tabular}

The data that do not have a similar letter are notably different $(p$-value $<0.05)$. With multiple superscripts, the values were calculated using Tukey's multiple comparison test. Results are presented as mean \pm standard deviation. $\mathrm{ND}=$ not determined. table solvent for higher yield of extraction. Sultana et al. also reported that aqueous methanol is the most suitable solvent.

The choice of the solvents to be used in the present study is in line with the goal of this work. It requires a solvent that can extract a wide range of compounds, such as methanol. Once the quality of the sample has been evaluated through this rapid test, one can use ethanol or water to extract the plant for consumption purposes.

\subsection{AGI Activity}

Table 1 shows the AGI activity of P. malayana leaf extracts in various ratios of methanol-water. It is shown as the $\mathrm{IC}_{50}$ value in $\mu \mathrm{g} / \mathrm{mL}$, the minimum value representing the maximum inhibitory activity. There were no significant differences found in the inhibition potential of the $0 \%$ and $50 \%$ methanol-water extracts. In contrast, the $25 \%, 75 \%$, and $100 \%$ methanol-water extracts exhibited notable differences $(p<0.05)$. The result shows that all extracts exhibited high AGI activity. The $100 \%$ methanol extract has the highest AGI activity with the $\mathrm{IC}_{50}$ value of $2.83 \mu \mathrm{g} / \mathrm{mL}$, and taken together it was found that P. malayana leaf extract has notable AGI activity. In contrast, Jemain et al. [16] reported that $P$. malayana leaf showed only $\alpha$-amylase inhibition $(15.7 \pm 0.8 \mu \mathrm{g} / \mathrm{mL})$ and no $\alpha$-glucosidase inhibition. This contrast could be due to the fact that they used dichloromethane as an extraction solvent following maceration, which is a technique for extraction. Due to the various absorbance conditions, methods of extraction and solvents used could alter the extraction yield and the plant bioactivity, as shown in a previous study [15,17-20].

\subsection{FTIR Spectra of the P. Malayana Extracts}

FTIR is one of the most extensively used analytical techniques, not only used to identify chemical constituents but also to elucidate structural components [11]. FTIR spectra of different ratios of 
methanol-water extracts $(0,25,50,75$, and $100 \%$ methanol) obtained from the $P$. malayana leaves are presented in Figure 1. As per the vibrational mode, the assigned peaks' attribution of the P. malayana FTIR spectra are shown in Table 2.

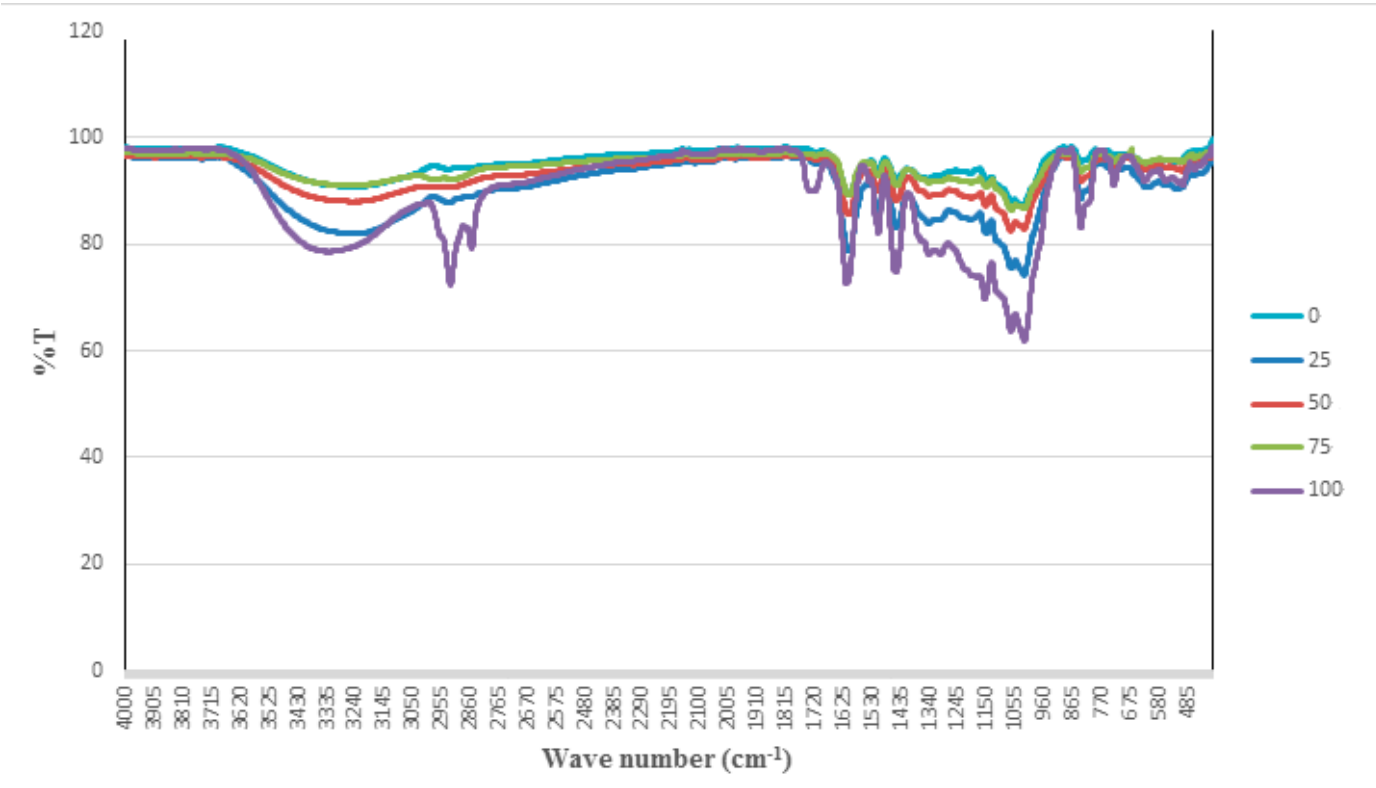

Figure 1. Infrared spectra of Psychotria malayana leaf extracts $(0 \%, 25 \%, 50 \%, 75 \%$, and $100 \%$ methanol-water).

Table 2. Functional groups of P. malayana leaf extracts as seen by Fourier Transform Infrared Spectroscopy (FTIR) analysis [21].

\begin{tabular}{ccc}
\hline Region of Wavenumber $\left(\mathbf{c m}^{-\mathbf{1}}\right)$. & Functional Group & Name of Functional Group Attribution \\
\hline 3010 to 3670 & O-H stretch & Phenols, alcohols, and carboxylic acid \\
2795 to 3010 & C-H stretch & Aromatics/aldehydes, alkanes, and alkenes \\
1666 to 1730 & C=O stretch & Aldehydes/primary amides, carboxylic acid, ester, and ketone \\
1550 to 1660 & $\mathrm{C}=\mathrm{C}$ & Alkenes \\
1300 to 1390 & $\mathrm{~N}=\mathrm{O}$ & Aliphatic nitro compounds \\
650 to 1000 & $\mathrm{C}=\mathrm{C}$ bend & Alkenes \\
430 to 800 & C-H & 430 to 800 \\
\hline
\end{tabular}

$\mathrm{N}=$ nitrogen; $\mathrm{O}=$ oxygen; $\mathrm{H}=$ hydrogen; $\mathrm{C}=$ carbon.

Several functional groups, including alkanes, alkene, aromatics, and carbonyl groups, were found. Besides these, hydroxyl and amino groups were identified. The peak found for the bond stretch frequencies for $\mathrm{O}-\mathrm{H}$ at $3010-3670 \mathrm{~cm}^{-1}$ indicates alcohol, phenol, and carboxylic acid groups. The $\mathrm{C}-\mathrm{H}$ stretching vibrations in the alkanes, alkenes, aldehydes, and aromatic groups produced a strong band in the region of $2795-3010 \mathrm{~cm}^{-1}$. The peak found at $1666-1730 \mathrm{~cm}^{-1}$ indicates the existence of the carbonyl group $(\mathrm{C}=\mathrm{O})$, which means ester, carboxylic acid, and carbonyl compounds. Besides this, the peaks showed at 1550 to $1660 \mathrm{~cm}^{-1}$ and near $1500 \mathrm{~cm}^{-1}$, respectively, reveal the existence of alkenes $(\mathrm{C}=\mathrm{C})$ and secondary aromatic amines $(\mathrm{N}-\mathrm{H})$. C-N stretching indicating aromatic amines showed a strong band in the region of $1250-1350 \mathrm{~cm}^{-1}$, and $C=C$ bending, which represents alkene, was observed in the region of $650-1000 \mathrm{~cm}^{-1}$. The peak found in the area of 430 to $800 \mathrm{~cm}^{-1}$ indicated alkanes and out-of-plane C-H bending of the aromatic end [21].

Based on the spectra, it was found that the peak representing $\mathrm{C}-\mathrm{H}$ stretching was more prominent in the $100 \%$ methanol extract, whereas the same peak was absent in the other extracts $(0,25,50$, and $75 \%$ methanol). This observation indicates the existence of alkanes, alkenes, aldehydes, and aromatic compounds in the $100 \%$ methanol extract. 
Besides that, the peak of $\mathrm{C}=\mathrm{O}$ stretching was more significant in the $100 \%$ methanol extract than in the other extracts, which indicates the presence of ester, carboxylic acid, and carbonyl compounds in the $100 \%$ methanol extract. Furthermore, the peak indicating the presence of an amino compound was sharp in the $100 \%$ methanol extract, while in other extracts it appeared as a tiny shoulder, confirming the presence of aromatic amines [21]. Apart from this, peaks of $\mathrm{C}=\mathrm{C}$ and $\mathrm{C}-\mathrm{H}$ out-of-plane bending were found to be more significant in the $100 \%$ methanol extract in comparison with all other extracts. Some alpha-glucosidase inhibitors identified by gas chromatography-mass spectrometry (GC-MS)-based metabolomics were bearing the aforementioned functional groups related to the active compounds, including alpha-tocopherol (vitamin E), palmitic acid, beta-tocopherol, 1-monopalmitin, and stigmast-5-ene [22-24], which may be present in P. malayana.

Conclusively, gradient extraction solvents showed different effects in the yield as well as the bioactivity of the extract. Furthermore, the selectivity of the compounds and their bioactivity were also affected by variation in solvent polarities [15,17-20].

\subsection{Multivariate Data Analysis (MVDA)}

While most statistical techniques focus on just one or two variables, Multivariate data analysis allows more than two variables to be analysed at once. In MVDA, OPLS is one of the most familiar models. An impressive separation can be obtained by orthogonal partial least square-discriminant analysis (OPLS-DA) [25]. Wagner et al. [26] discussed the improved classification results based on the OPLS model. Yuliana et al. [27] also reported that OPLS is a suitable tool for studying the chemical profile-activity correlation.

The discrimination of the samples employing the OPLS model is shown in Figure 2. In this OPLS model, the first matrix, considered as the $x$-variable, indicates the data acquired from the FTIR spectra. In contrast, the second matrix, considered as the $y$-variable, represents the per $\mathrm{IC}_{50}$ of AGI activity. This model shows two components $(1+1+0)$ with a $\mathrm{R}^{2} \mathrm{Y}$ and a $\mathrm{Q}^{2} \mathrm{Y}$ (cumulative) of 65.9 and $50.5 \%$, respectively. The samples having high AGI activity (100\% and $25 \%$ methanol-water extracts) are on the positive side of the OPLS component 1 and differentiated from the extracts having less activity (75\%, 50\%, and 0\% methanol-water extracts) that were clustered at the negative semicircle (Figure 3).

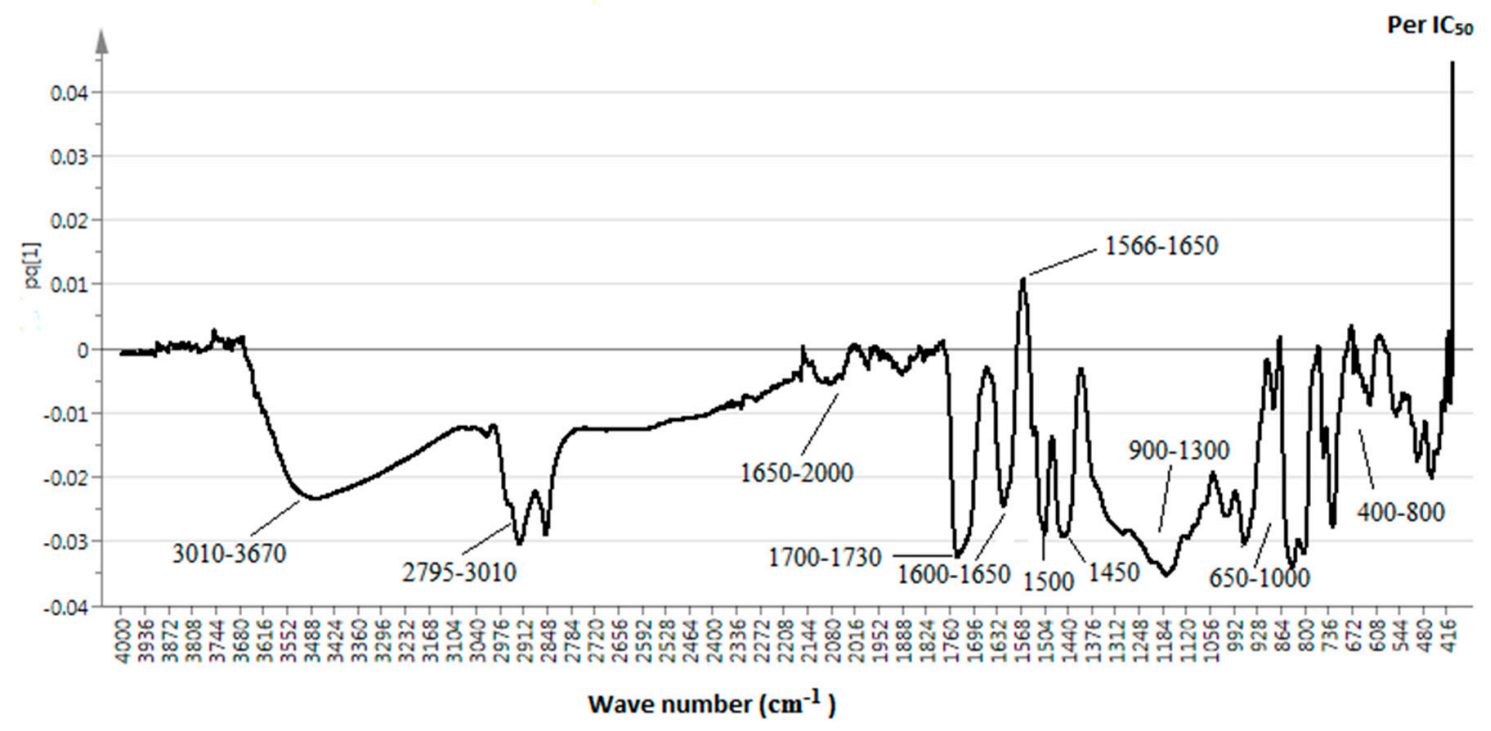

Figure 2. OPLS line loading plot of P. malayana Jack leaf extracts. 


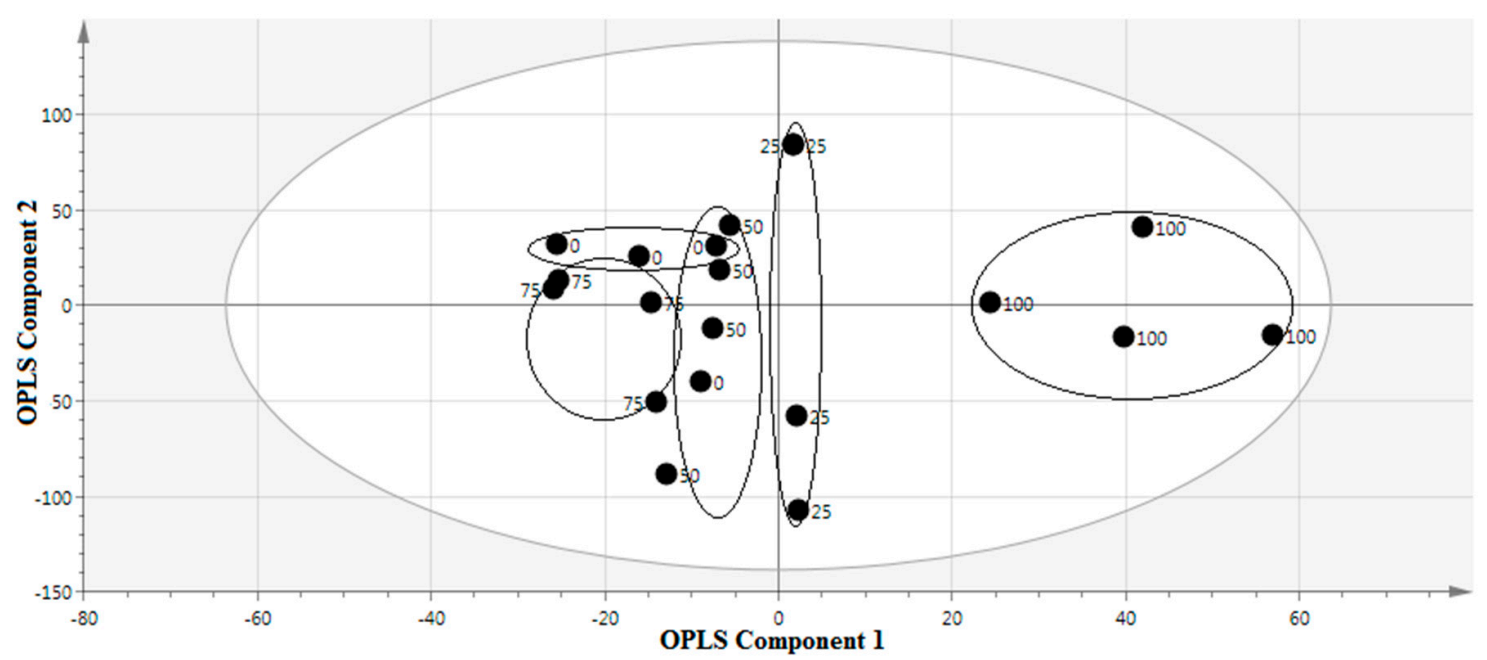

Figure 3. Orthogonal partial least square (OPLS) score plot of various solvent ratios of $P$. malayana Jack leaf extracts.

Table 3 shows the interrelation between the wave number from the FTIR spectra, considered as the $\mathrm{x}$-variable, and the AGI activity (per $\mathrm{IC}_{50}$ ), considered as the $\mathrm{y}$-variable. The plot exhibits the spectral data that influence the AGI activity. The peaks present at the negative axis of pq [1] of the plot correlate with the AGI activity and vice versa. The peaks found at $3010-3670 \mathrm{~cm}^{-1}$ and 2795-3010 $\mathrm{cm}^{-1}$, relating to the signals from the alpha-glucosidase inhibitors, showed bond stretch frequencies for $\mathrm{O}-\mathrm{H}$ and $\mathrm{C}-\mathrm{H}$, respectively. These peaks indicate the presence of alcohol, alkanes, alkenes, aromatics, or aldehydes. Besides this, the peaks at $2000-1650 \mathrm{~cm}^{-1}, 1700-1730 \mathrm{~cm}^{-1}$, and $1600-1650 \mathrm{~cm}^{-1}$ indicate $\mathrm{C}-\mathrm{H}$ (bending), bond stretch frequencies for $\mathrm{C}=\mathrm{O}$, and bond stretch frequencies for $\mathrm{C}=\mathrm{C}$, respectively, which show the presence of aromatic compounds, carboxylic acid, and alkenes. Furthermore, the peaks found at $1450 \mathrm{~cm}^{-1}$ and $900-1300 \mathrm{~cm}^{-1}$ showed the presence of C-H bending and C-O (stretch) of secondary aromatic amines, an alkane, and alcohol, and ethers, esters, a carboxylic acid, and anhydrides, respectively. The presence of $\mathrm{N}-\mathrm{H}$ bending was due to the appearance of a peak in the $1550 \mathrm{~cm}^{-1}$ region. Additionally, the peaks found at $650-1000 \mathrm{~cm}^{-1}$ and $430-800 \mathrm{~cm}^{-1}$ show $\mathrm{C}=\mathrm{C}$ (bending) and a long chain of $\mathrm{C}-\mathrm{H}$ (out-of-plane bending), respectively.

Table 3. The actual and predicted AGI activity of the $100 \%$ methanol extract of the external samples of P. malayana leaves.

\begin{tabular}{ccc}
\hline Number of Sources & $\begin{array}{c}\text { Actual AGI Activity } \\
\text { IC }_{\mathbf{5 0}} \\
(\mu \mathbf{g} / \mathbf{m L})\end{array}$ & Predicted AGI Activity \\
\hline 1 & $5.70 \pm 0.44^{\mathrm{a}}$ & High Activity \\
2 & $5.58 \pm 0.38^{\mathrm{a}}$ & High Activity \\
3 & $2.63 \pm 0.35^{\mathrm{c}}$ & High Activity \\
4 & $3.80 \pm 0.81^{\mathrm{b}, \mathrm{c}}$ & High Activity \\
5 & $5.10 \pm 0.70^{\mathrm{a}, \mathrm{b}}$ & High Activity \\
6 & $5.60 \pm 0.66^{\mathrm{a}}$ & High Activity \\
\hline
\end{tabular}

Results are presented as mean \pm standard deviation.The data that do not have a similar letter are notably different ( $p$-value $<0.05)$. With multiple superscripts, the values were calculated and represented using Tukey's multiple comparison test.

Apart from this, the peaks present at the positive side of pq [1] of the plot (Figure 4) indicate the functional groups that do not make any contribution to the AGI activity. It shows the bond stretch frequencies for $\mathrm{C}=\mathrm{C}$ at $1566-1650 \mathrm{~cm}^{-1}$ indicating the cyclic alkene. This finding can be a guideline for future bioactive compounds isolation. 


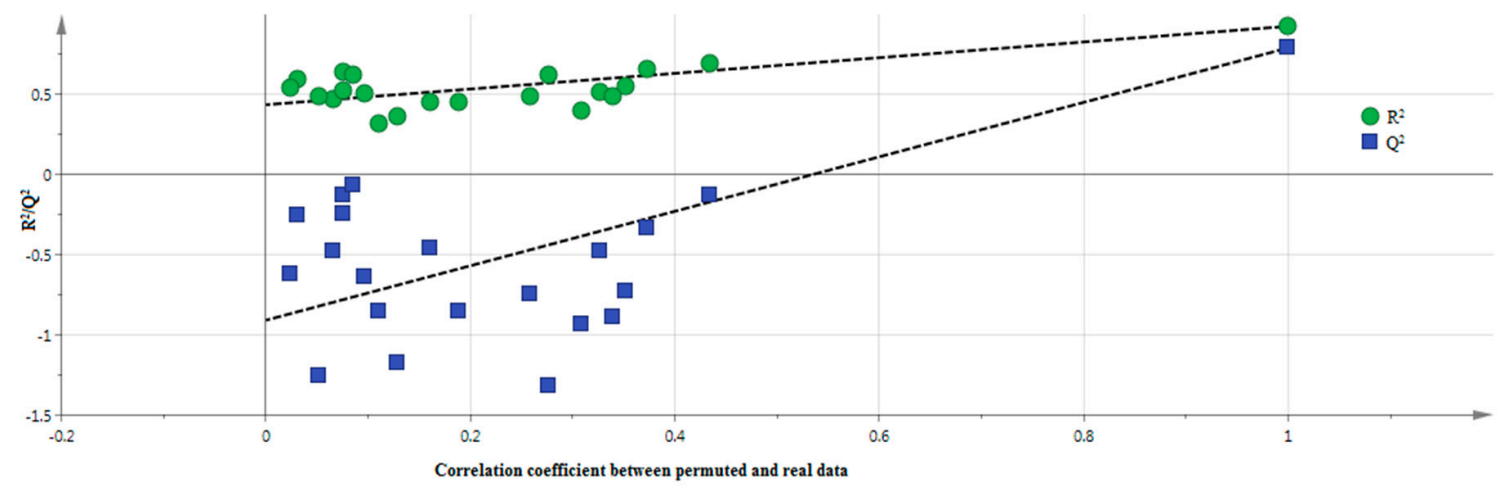

Figure 4. OPLS permutation plot of all P. malayana Jack leaf extracts.

Hadi et al. [7] identified major alkaloids, hodgkinsines, and other compounds, including calycanthine, (+/-)-chimonanthine, meso-chimonanthine, 2-ethyl-6-methylpyrazine, and 3-methyl-1,2,3,4-tetrahydro- $\gamma$-carboline from the leaves of P. malayana. Matssura et al. [9] illustrated the analgesic activities of hodgkinsine, (+)-chimonanthine, and meso-chimonanthine. Hadi [8] found the anti-bacterial activities of LPM-574, which is a derivative of hodgkinsine. Chebib et al. [10] reported the anti-convulsant effect of calycanthine.

\subsection{MVDA Validation}

The calibration model's validation is vital for ensuring the authenticity of the predictive model. For the achievement of reliable data, it is crucial to overcome the risk of over-fitting the data. Model validation may be performed by cross-validation [28]. The ultimate predictive capacity of the model can be measured, and from this cross-validation the importance of the latent variable can be assessed [29].

From the obtained data shown in Figure 4, it can be concluded that the validity of the model developed is appropriate, because the total sum of the squares intercepting the $Y$-value and the predictive ability of the model intercepting the Y-value were less than 0.4 and 0.05 , respectively [29]. In the present study, both of the model's intercepting Y-values met the specifications. Its residuals were linear with an $\mathrm{R}^{2}$ of 0.9255 , which represents the match between the experimental data and the model's predictions (Figure 5).

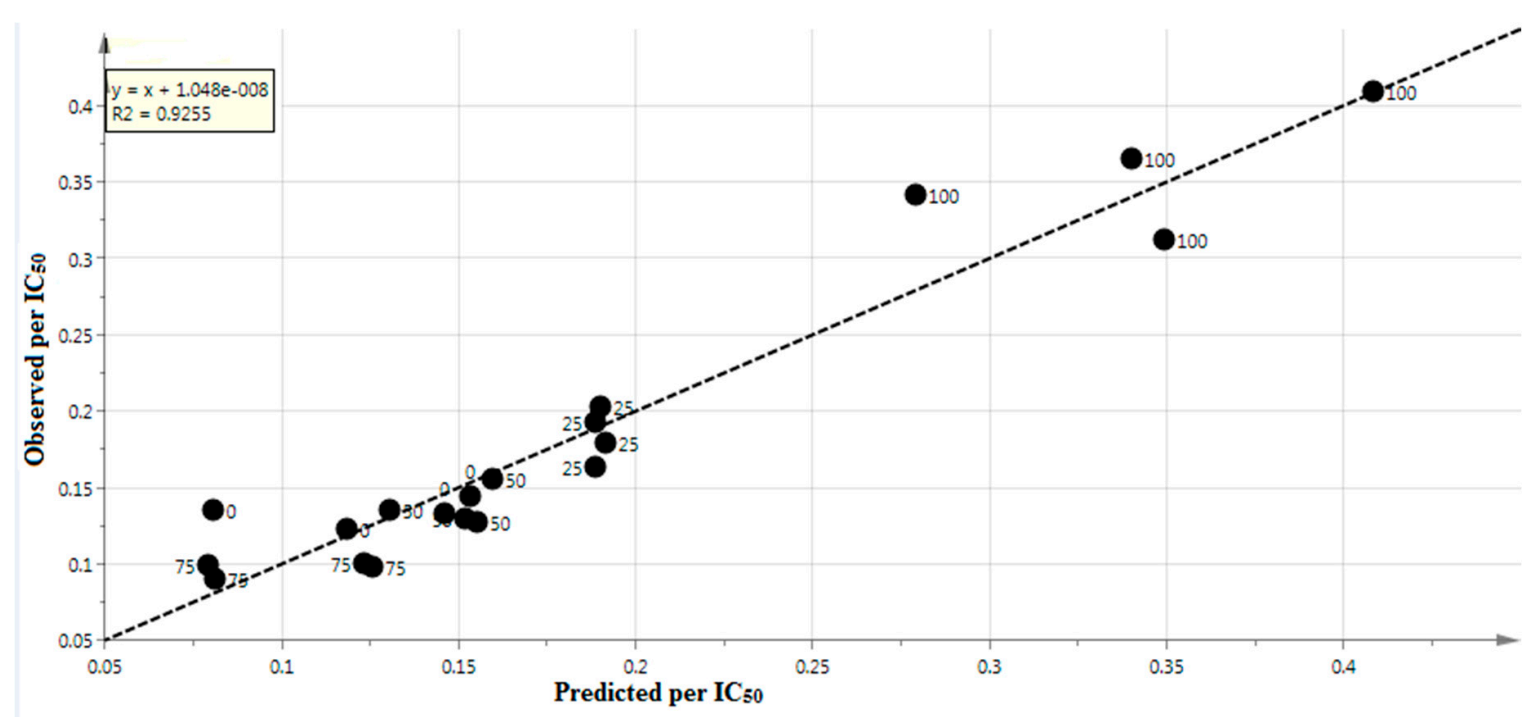

Figure 5. Observed versus predicted per $\mathrm{IC}_{50}$ data from P. malayana extracts. 
Regarding the acceptability and predictability of the model, it is vital to include external samples [30]. A total of six external samples were extracted using 100\% methanol, and Table 3 shows the original and predicted data for AGI activity. Based on the FTIR spectra, the AGI activity for all six samples was predicted and measured using the calibration model. All six external extracts showed high activity. Therefore, for predicting the AGI activity of P. malayana leaf extracts, the developed calibration model is valid.

\section{Materials and Methods}

\subsection{Materials}

Every single organic chemical purchased from Merck (Darmstadt, Germany) (methanol, dimethyl sulfoxide) was of analytical quality. Purchased standard quercetin was from Sigma-Aldrich (St. Louis, MO, USA); whereas the AGE, from yeast maltase, was obtained from Megazyme, Ireland. Besides this, the $\alpha$-glucosidase (PNPG) was obtained from Sigma-Aldrich.

\subsection{Collection and Preparation of Sample}

The P. malayana plant was acquired from Cermin Nan Gedang in the district of Sarolangun, Jambi, Indonesia, and defined by a botanist, Shamsul Khamis. The plant sample was deposited at the KOP Herbarium, IIUM, Kuantan, for authentication. For seven days, the leaves were dried at ambient temperature and then powdered utilizing a universal cutting mill bought from Fritsch, Germany. The powdered plant leaves were preserved at $-80^{\circ} \mathrm{C}$ before extraction $[22,31]$.

\subsection{Preparation of Samples}

About $400 \mathrm{~g}$ of P. malayana leaves were collected from six different areas of Indonesia for the purpose of validation. The leaves were cleaned and dried for seven days at ambient temperature. After that, the leaves were ground into powder utilizing a universal cutting mill (Fritsch, Germany) and preserved in a freezer having the temperature of $-80{ }^{\circ} \mathrm{C}[22,31]$. The crude extracts were prepared with $100 \%$ methanol after sonication for $30 \mathrm{~min}$. AGI activity was determined for each extract, and FTIR analysis was used to evaluate the inhibitory activity of $\alpha$-glucosidase utilizing multivariate data analysis [22,30].

\subsection{Preparation of P. Malayana Extracts}

For extraction, a common technique was adapted with approximately $1 \mathrm{~g}$ of plant powder. The extraction process was carried out through the sonication technique. The $1 \mathrm{~g}$ of plant powder was immersed in $30 \mathrm{~mL}$ of water and methanol at different ratios $(0,25,50,75$, and 100\% v/v) and sonicated for $30 \mathrm{~min}$ at $40^{\circ} \mathrm{C}$. The filtrate was then obtained utilizing Whatman ${ }^{\circledR}$ grade one filter paper. A rotary evaporator was used at the temperature of $40{ }^{\circ} \mathrm{C}$ to remove any remaining solvents. Each extract was processed in four replicates, followed by storage at $-80^{\circ} \mathrm{C}$ before further use. For each of the five different methanol concentrations, a total of four replicates were prepared, resulting in 20 samples in total. Each extract of P. malayana was assessed for in vitro AGI activity and analyzed utilizing FTIR. The percentage of extraction yield was measured using the following formula:

$$
\text { Extraction yield }(\%, w / w)=\mathrm{Wt}_{\mathrm{a}} / \mathrm{Wt}_{\mathrm{b}} \times 100 \%
$$

where $W t_{a}$ indicates the final weight of the freeze-dried extract, and $W t_{b}$ is the initial weight of the raw plant powder [22].

\subsection{AGI Assay}

The in vitro AGI activity was determined following the assay of Javadi et al. [22]. Quercetin (positive control) is a well-known AGE inhibitor, prepared by dissolving 2 milligrams in 1 milliliter of dimethyl sulfoxide (DMSO). On the other hand, the substrate $\rho$-nitrophenyl- $\rho$-D-glucopyranoside 
(PNPG) is prepared by weighing 6 milligrams of the substrate and dissolving it in 20 milliliters of 50 millimolar phosphate buffer prior to the adjustment of the $\mathrm{pH}$ value to 6.5 using sodium hydroxide solution. The dried plant extracts were prepared in the same way as the quercetin. Ten microliters $(10 \mu \mathrm{L})$ of quercetin (positive control), the samples, and DMSO (negative control) were added into a 96-well plate. One hundred microliters of 30 millimolar phosphate buffer and 15 microliters of the enzyme were added into the reaction mixture. The blank was the one without enzyme. After five minutes of incubation at ambient temperature, 75 microliters of PNPG was added to the samples and the blank mixture. After another $15 \mathrm{~min}$ of incubation, the catalytic reaction was halted by the addition of 50 microliters of glycin. The absorbance was taken at $405 \mathrm{~nm}$ utilizing a microplate reader (Tecan Nanoquant Infinite M200, Tecan, Männedorf, Switzerland). The IC $_{50}$ was calculated from the linear regression analysis. $\mathrm{IC}_{50}$ is an important tool for measuring the efficacy and potency of an inhibitor; it represents the amount of inhibitor needed to halve the response [32]. All determinations were performed in triplicate. The AGI activity (\%) was determined using the formula below:

$$
\text { Inhibitory activity }(\%)=\left[\left(\mathrm{A}_{\text {control }}-\mathrm{A}_{\text {sample }}\right) / \mathrm{A}_{\text {control }}\right] \times 100 \%
$$

where $\mathrm{A}_{\text {control }}$ indicates the negative control's absorbance, and $\mathrm{A}_{\text {sample }}$ represents the sample's or positive control's absorbance [33].

\subsection{FTIR Analysis}

The experiment was carried out with an FTIR spectrometer (Perkin Elmer Inc., Waltham, MA, USA) fitted with a horizontally attenuated total reflectance system with a diamond crystal. The instrument was adjusted to ambient temperature before operation. A minimal quantity of each freeze-dried sample was put onto the diamond crystal using a washed spatula [34]. FTIR spectra were assessed in the wave region of $400-4000 \mathrm{~cm}^{-1}$ and at the resolution of $4 \mathrm{~cm}^{-1}$. The Attenuated total reflection (ATR) crystal was cleansed with utmost care between measurements. The data were collected and processed through the software Perkin Elmer Spectrum version 10.03.09 (Waltham, MA, USA). The data were then measured using multivariate data analysis [30].

\subsection{Statistical Analysis}

All data are shown as mean \pm standard deviation (SD) utilizing Minitab 17 (Minitab Inc., State College, PA, USA). One-way analysis of variance (ANOVA) along with a Tukey's comparison test were used to assess the differences, which were considered significant at $p<0.05$ with a confidence interval of $95 \%$. In the interim, the spectra acquired from the infrared assay were changed into ASCII format. For multivariate data analysis (MVDA), the data were then translated into Microsoft Excel format and brought up in the Simca $\mathrm{P}^{+} 14.0$ software (Umetrics, Umeå, Sweden) using an orthogonal partial least square (OPLS) model for the AGI activity and the spectral data.

\section{Conclusions}

This research explored the potential anti-diabetic activity of P. malayana leaf extracts at different methanol-water ratios $(0 \%, 25 \%, 50 \%, 75 \%$, and 100\% methanol-water). The 100\% methanol-water extract showed the maximum inhibitory activity. The correlation of FTIR spectra and AGI activity identified the functional groups that are able to induce AGI activity, namely hydroxyl (O-H), alkenyl $(\mathrm{C}=\mathrm{C})$, methylene $(\mathrm{C}-\mathrm{H})$, carbonyl $(\mathrm{C}=\mathrm{O})$, and secondary amine $(\mathrm{N}-\mathrm{H})$ groups. This analysis has developed a validated statistical model, with an $R^{2} Y$ value of 0.9255 indicating the fitness of the model. The AGI activity of P. malayana was predicted using this validated statistical model. This finding shows that the developed model is statistically valid to predict AGI activity, which is very useful as a tool in the quality control of this plant.

Author Contributions: Conceptualization, T.S.N. and A.K.; methodology, T.S.N. and A.K.; software, T.S.N. and A.K.; validation, T.S.N. and A.K.; formal analysis, T.S.N. and A.K.; investigation, T.S.N. and A.K.; resources, 
T.S.N. and A.K.; data curation, T.S.N. and A.K.; writing-original draft preparation, T.S.N.; writing-review and editing, S.A.M.K, H.R.E.-S., T.S.N., A.K., and A.Y.F.K.; visualization, T.S.N. and A.K.; supervision, A.K., Q.U.A., I.E.R., and Z.I.; project administration, T.S.N., R.P. and A.K.; funding acquisition, S.A.M.K., H.R.E.-S., T.S.N., R.P. and A.K. All authors have read and agreed to the published version of the manuscript.

Funding: This work was supported by the Malaysian Ministry of Education for the Fundamental Research Grant Scheme [FRGS-19-0880697] and the Swedish Research Council Vetenskapsrådet (VR Grant 2016-05885).

Acknowledgments: T.S.N. would like to thank the Bangabandhu Science and Technology Fellowship Trust, Ministry of Science and Technology of Bangladesh for the granting of her Ph.D. fellowship. A. Khatib acknowledges the Malaysian Ministry of Education for the Fundamental Research Grant Scheme [FRGS-19-0880697]; S.A.M.K. and H.R.E.-S. are very grateful to the Swedish Research Links Grant VR 2016-05885 and the Department of Molecular Biosciences, Wenner-Grens Institute, Stockholm University, Sweden, for financial support.

Conflicts of Interest: The authors declare no conflict of interest.

\section{References}

1. Roglic, G. WHO Global Report on Diabetes: A Summary. Int. J. Noncommun. Dis. 2016, 1, 3-8. [CrossRef]

2. Mohan, S.; Nandhakumar, L. Role of Various Flavonoids: Hypotheses on Novel Approach to Treat Diabetes. J. Med. Hypotheses Ideas 2014, 8, 1-6. [CrossRef]

3. IDF. IDF Diabetes Atlas; International Diabetes Federation: Brussels, Belgium, 2015.

4. Hurt, R.T.; Kulisek, C.; Buchanan, L.A.; McClave, S.A. The Obesity Epidemic: Challenges, Health Initiatives, and Implications for Gastroenterologists. Gastroenterol. Hepatol. (N. Y). 2010, 6, 780-792.

5. Chaudhury, A.; Duvoor, C.; Dendi, R.; Sena, V.; Kraleti, S.; Chada, A.; Ravilla, R.; Marco, A.; Shekhawat, N.S.; Montales, M.T. Clinical Review of Antidiabetic Drugs: Implications for Type 2 Diabetes Mellitus Management. Front. Endocrinol. (Lausanne) 2017, 8, 1-12. [CrossRef]

6. Situmorang, R.O.; Harianja, A.H.; Silalahi, J. Karo's Local Wisdom: The Use of Woody Plants for Traditional Diabetic Medicines. Indones. J. For. Res. 2015, 2, 121-130. [CrossRef]

7. Hadi, S.; Rahmawati, K.P.; Asnawati, D.; Ersalena, V.F.; Azwari, A. Characterization Of Alkaloids From The Leaves of Psychotria malayana Jack of Lombok Island on the Basis of Gas Chromatography-Mass Spectroscopy. J. Pure Appl. Chem. Res. 2014, 3, 108-113. [CrossRef]

8. Hadi, S. Bioactive Alkaloids from Medicinal Plants of Lombok. Ph.D. Thesis, University of Wollongong, Wollongong, NSW, Australia, 10 October 2002.

9. Matsuura, H.N.; Porto, D.D.; Fett-Neto, A.G. Bioactive Alkaloids from South American Psychotria and Related Rubiaceae. Nat. Prod. 2013, 119-147. [CrossRef]

10. Chebib, M.; Duke, R.K.; Duke, C.C.; Connor, M.; Mewett, K.N.; Johnston, G.A.R. Convulsant Actions of Calycanthine. Toxicol. Appl. Pharmacol. 2003, 190, 58-64. [CrossRef]

11. Nagarajan, D.; Kumar, T.R. Fourier Transform Infrared Spectroscopy Analysis of Garlic (Allium). Int. J. Zool. Stud. 2017, 2, 11-14.

12. Ashokkumar, R.; Ramaswamy, M. Phytochemical Screening by FTIR Spectroscopic Analysis of Leaf Extracts of Selected Indian Medicinal Plants. J. Curr. Microbiol. Appl. Sci. 2014, 3, 395-406.

13. Kumar, S.; Narwal, S.; Kumar, V.; Prakash, O. $\alpha$-Glucosidase Inhibitors from Plants: A Natural Approach to Treat Diabetes. Pharmacogn. Rev. 2011, 5, 19-29. [CrossRef]

14. Khatib, A.; Perumal, V.; Ahmed, Q.U.; Uzir, B.F.; Abas, F.; Murugesu, S. Characterization of Antioxidant Activity of Momordica Charantia Fruit by Infrared-Based Fingerprinting. Anal. Lett. 2017, 50, 1977-1991. [CrossRef]

15. Sultana, B.; Anwar, F.; Ashraf, M. Effect of Extraction Solvent/Technique on the Antioxidant Activity of Selected Medicinal Plant Extracts. Molecules 2009, 14, 2167-2180. [CrossRef] [PubMed]

16. Jemain, M.R.M.; Musa'adah, M.N.; Rohaya, A.; Rashid, L.A.; Hadiani, I.N. In Vitro Antihyperglycaemic Effects of Some Malaysian Plants. J. Trop. For. Sci. 2011, 23, 467-472. [CrossRef]

17. Yan, J.; Shen, Y.; Wang, Y.; Luan, X.; Guo, M.; Li, C. The Effects of Different Extraction Methods on the Physicochemical Property and Antioxidant Activity of Amygdalus Pedunculatus Seed Oil. J. Appl. Bot. Food Qual. 2016, 89, 135-141. [CrossRef]

18. Sharif, M.F.; Bennett, M.T. The Effect of Different Methods and Solvents on the Extraction of Polyphenols in Ginger (Zingiber Officinale). J. Teknol. 2016, 78, 49-54. [CrossRef] 
19. Thouri, A.; Chahdoura, H.; El Arem, A.; Hichri, A.O.; Hassin, R.B.; Achour, L. Effect of Solvents Extraction on Phytochemical Components and Biological Activities of Tunisian Date Seeds (Var. Korkobbi and Arechti). BMC Complement. Altern. Med. 2017, 17, 248-257. [CrossRef] [PubMed]

20. Van Ngo, T.; Scarlett, C.J.; Bowyer, M.C.; Ngo, P.D.; Van Vuong, Q. Impact of Different Extraction Solvents on Bioactive Compounds and Antioxidant Capacity from the Root of Salacia Chinensis, L.J. Food Qual. 2017, 2017,1-8. [CrossRef]

21. Pavia, D.L.; Lampman, G.M.; Kriz, G.S.; Vyvyan, J.A. Introduction to Spectroscopy, 5th ed.; Cengage Learning: Stamford, CT, USA, 2014.

22. Javadi, N.; Abas, F.; Hamid, A.A.; Simoh, S.; Shaari, K.; Ismail, I.S.; Mediani, A.; Khatib, A. GC-MS-Based Metabolite Profiling of Cosmos Caudatus Leaves Possessing Alpha-Glucosidase Inhibitory Activity. J. Food Sci. 2014, 79, C1130-C1136. [CrossRef]

23. Murugesu, S.; Ibrahim, Z.; Ahmed, Q.U.; Yusoff, N.I.N.; Uzir, B.F.; Perumal, V.; Abas, F.; Saari, K.; El-Seedi, H.; Khatib, A. Characterization of $\alpha$-Glucosidase Inhibitors from Clinacanthus Nutans Lindau Leaves by Gas Chromatography-Mass Spectrometry-Based Metabolomics and Molecular Docking Simulation. Molecules 2018, 23, 2402. [CrossRef]

24. Alam, M.A.; Zaidul, I.S.M.; Ghafoor, K.; Sahena, F.; Hakim, M.A.; Rafii, M.Y.; Abir, H.M.; Bostanudin, M.F.; Perumal, V.; Khatib, A. In Vitro Antioxidant and, $\alpha$-Glucosidase Inhibitory Activities and Comprehensive Metabolite Profiling of Methanol Extract and Its Fractions from Clinacanthus Nutans. BMC Complement. Altern. Med. 2017, 17, 1-10. [CrossRef] [PubMed]

25. Whelehan, O.P.; Earll, M.E.; Johansson, E.; Toft, M.; Eriksson, L. Detection of Ovarian Cancer Using Chemometric Analysis of Proteomic Profiles. Chemom. Intell. Lab. Syst. 2006, 84, 82-87. [CrossRef]

26. Wagner, S.; Scholz, K.; Sieber, M.; Kellert, M.; Voelkel, W. Tools in Metabonomics: An Integrated Validation Approach for LC-MS Metabolic Profiling of Mercapturic Acids in Human Urine. Anal. Chem. 2007, 79, 2918-2926. [CrossRef] [PubMed]

27. Yuliana, N.D.; Khatib, A.; Verpoorte, R.; Choi, Y.H. Comprehensive Extraction Method Integrated with NMR Metabolomics: A New Bioactivity Screening Method for Plants, Adenosine A1 Receptor Binding Compounds in Orthosiphon Stamineus Benth. Anal. Chem. 2011, 83, 6902-6906. [CrossRef]

28. Trivedi, D.K.; Iles, R.K. The Application of SIMCA P+ in Shotgun Metabolomics Analysis of ZIC ${ }^{\circledR}$ HILIC-MS Spectra of Human Urine-Experience with the Shimadzu IT-TOF and Profiling Solutions Data Extraction Software. J. Chromatogr. Sep. Tech. 2012, 3,1-5. [CrossRef]

29. Eriksson, L.; Johansson, E.; Kettaneh-Wold, N.; Trygg, J.; Wikström, C.; Wold, S. Process Analytical Technology (PAT) and Quality by Design (QbD). In Multi- and Megavariate Data Analysis, 3rd ed.; Umetrics Academy: Umea, Sweden, 2006; Volume 1.

30. Sharif, K.M.; Rahman, M.M.; Azmir, J.; Khatib, A.; Hadijah, S.; Mohamed, A.; Sahena, F.; Zaidul, I.S.M. Orthogonal Partial Least Squares Model for Rapid Prediction of Antioxidant Activity of Pereskia Bleo by Fourier Transform Infrared Spectroscopy. Anal. Lett. 2014, 47, 2061-2071. [CrossRef]

31. Abd Aziz, S.M.; Low, C.N.; Chai, L.C.; Abd Razak, S.S.N.; Selamat, J.; Son, R.; Sarker, M.Z.I.; Khatib, A. Screening of Selected Malaysian Plants against Several Food Borne Pathogen Bacteria. Int. Food Res. J. 2011, 18, 1195-1201.

32. Aykul, S.; Martinez-Hackert, E. Determination of Half-Maximal Inhibitory Concentration Using Biosensor-Based Protein Interaction Analysis. Anal. Biochem. 2016, 508, 97-103. [CrossRef]

33. Burlingham, B.T.; Widlanski, T.S. An Intuitive Look at the Relationship of Ki and $\mathrm{IC}_{50}$ : A More General Use for the Dixon Plot. J. Chem. Educ. 2003, 80, 214-218. [CrossRef]

34. Nurraihana, H.; Norfarizan-Hanoon, N.A. Phytochemistry, Pharmacology and Toxicology Properties of Strobilanthes Crispus. Int. Food Res. J. 2013, 20, 2045-2056.

Sample Availability: Herbal samples are stored in Kulliyyah of Pharmacy's herbarium IIUM Kuantan, and available from the authors. 